\title{
"As if There is a Stranger in my House Now:" Psychological Ambiguous Loss Experienced by Spousal Caregivers of Patients of Anxiety Disorders
}

\author{
Liebe M. E. P. P. Polia, Sri Redatin Retno Pudjiati ${ }^{\mathrm{b}}$, and Efriyani Djuwita ${ }^{\mathrm{c}}$
}

${ }^{a}$ Faculty of Psychology, Universitas Indonesia, Depok, Indonesia; ${ }^{b}$ Department of Developmental Psychology, Faculty of Psychology, Universitas Indonesia, Depok, Indonesia;

${ }^{c}$ Department of Developmental Psychology, Faculty of Psychology, Universitas Indonesia, Depok, Indonesia

*Corresponding author:

Sri Redatin Retno Pudjiati

Department of Developmental Psychology

Faculty of Psychology, Universitas Indonesia

Jl. Lkr. Kampus Raya, Depok, Jawa Barat

Indonesia, 16424

Tel.: +62 217270004

Email address: retno-pj@ui.ac.id 


\title{
"As if There is a Stranger in my House Now:" Psychological Ambiguous Loss Experienced by Spousal Caregivers of Patients of Anxiety Disorders
}

\begin{abstract}
Psychological ambiguous loss (PAL) affects varied populations including the spousal caregivers of people who suffer from chronic mental disorders. Anxiety disorders (AD) represent a common and chronic mental disorder that exerts significant impact on patients as well as their spousal caregivers. To date, only few studies have focused on PAL experienced by spousal caregivers of patients of anxiety disorders (SCPAD). This study is needed to obtain additional knowledge that will help experts gain a better understanding of the PAL experienced by SCPAD. As a consequence, public awareness can be raised and better support can be provided through more effective PAL-related psychoeducation and interventions. The current study conducted an interpretative phenomenological analysis (IPA) to investigate the existence of PAL in five SCPAD in Jakarta and its environs, and to ascertain their lived experiences of this particular phenomenon. Eight overarching themes of SCPAD experiences emerged as a result of this investigation: a lack of understanding of $\mathrm{AD}$-related mental and behavioral changes, negative opinions and feelings toward their partners; the experience of loss; distress; acceptance; inadequate support from others; belief in God's sovereignty; and hope. The value addition, limitations, recommendations, and implications of this study are also discussed in the concluding section of the paper.
\end{abstract}

Keywords: psychological ambiguous loss, anxiety disorders, spousal caregivers, anxiety disorders sufferers, phenomenology

\section{Introduction}

Ambiguous loss (AL) is a stressor event. It may be described as a condition of an uncertain sense of bereavement without closure. It may result from not knowing whether a loved one is dead or alive, absent or present, or a situation that remains unverified and is thus unresolved (Boss, 1999). It usually occurs when a family member's absence or presence is unclear (Boss, Bryant \& Mancini, 2016). AL is a very difficult situation of strain for people to handle, and it is considered a common phenomenon that can occur in different populations. However, it is often overlooked (Boss, 1999, 2016; Boss, Bryant \& Mancini, 2016).

Psychological ambiguous loss (PAL) is a type of AL that occurs when the physical presence of a person exists while a loss or change in the individual's psychological state is experienced (Cridland, Jones, Magee \& Caputi, 2013). It happens when a family member or loved one is missing psychologically but still present physically. The 'missing person' is still alive, but is psychologically unavailable. Thus, PAL is described as psychological absence with physical presence, and families of people suffering from chronic mental disorders are categorized under this type of AL (Boss, 2004, 2016).

Anxiety disorders (AD) is a name given to a group of mental disorders characterized by excessive feelings of apprehension and fear that hamper the daily functioning of the person who suffers from them (DSM-V, 2013; Kring, Johnson, Davidson \& Neale, 2014)). ADs are 
the most common mental disorders suffered by people across the globe (Bandelow \& Michaelis, 2015; McLean, Asnaani, Litz, B.T. \& Hofmann, 2011; Remes, Brayne, van der Linde \& Lafortune, 2016). Such disorders are prevalent in the US (Kessler, Petukhova, Sampson, Zaslavsky \& Wittchen, 2012; Mc Lean dkk., 2011 (ADAA, 2014; NIMH, 2016)), in Australia, (Reavley, Cvetkovski \& Mackinnon, 2010), and in Europe (Wittchen et al., 2011). $6 \%$ of the Indonesian population, amounting to 14 million adults, is estimated to be suffering from mental / emotional disorders (Indonesian Ministry of Health, 2013). Observations made by a social media forum of Indonesian AD sufferers suggest an increase in this group's membership from 11000 members in early 2016 to almost 20000 members by mid-2018 (Anxietas Forum Indonesia, 2018).

As a chronic form of mental disorders (Bandelow \& Michaelis, 2015; Baxter, Vos, Scott, Ferrari \& Whiteford, 2014; Hofmeijer-Sevink et al., 2012; Kerig, Ludlow \& Wenar, 2012; Kessler, Petukhova, Sampson, Zaslavsky \& Wittchen, 2012), AD can interfere profoundly with the daily functioning of patients (Baxter, Vos, Scott, Ferrari \& Whiteford, 2014; Kasper, 2006; McLean, Asnaani, Litz, B.T. \& Hofmann, 2011; Senaratne, van Ameringen, Mancini \& Patterson, 2010), and their families (Baker, Procter \& Nicholas, 2009; Fadden, Bebbington \& Kuipers, 1987; Highet, Thompson \& McGrath, 2002; Hunt, Greene \& Whiting, 2016; Imran, Bhatti, Haider \& Azhar, 2010; Ollendick \& Allen, 2011; Priest, 2012; Rector, Bourdeau, Kitchen \& Joseph-Massiah, 2008; Rowe, 2012; Senaratne, van Ameringen, Mancini \& Patterson, 2010; Vermeulen, et al., 2015), including the SCPAD (Agarwal et al., 2017; Golics, Basra, Salek \& Finlay, 2013; Hunt, Greene \& Whiting, 2016; Imran, Bhatti, Haider \& Azhar, 2010; Priest, 2012; Rector, Bourdeau, Kitchen \& Joseph-Massiah, 2008; Vermeulen, et al., 2015).

$\mathrm{AD}$ sufferers may be physically present in the lives of their family members, but their psychological presence for the family, including for the SCPAD, may not be complete. Their cognitive functioning, particularly the working memory, may be impaired (Butters, Bhalla \& Andreescu, 2011; Gualtieri \& Morgan, 2008; Johnsen \& Asbjørnsen, 2008; Muller \& Roberts, 2005; Tempesta, Mazza \& Serroni, 2013; Yang et al., 2015). They may also be preoccupied by worrisome thoughts, predictions, and beliefs (Rector, Bourdeau, Kitchen \& JosephMassiah, 2008).

In addition, $\mathrm{AD}$ sufferers may experience affective and behavioral impairments ranging from excessive and irrational fear, tension, apprehensive feelings, withdrawal from feared situations or activities (Kerig, Ludlow \& Wenar, 2012; Rector, Bourdeau, Kitchen \& Joseph-Massiah, 2008), and dependence on others for support in the performance of daily tasks (Rector, Bourdeau, Kitchen \& Joseph-Massiah, 2008). Therefore, SCPAD must provide care and be supportive of their partners mentally, physically, financially, as well as socially (Hunt, Greene \& Whiting, 2016; Rowe, 2010; Vermeulen, et al., 2015).

Regarded from the perspective of PAL, SCPAD could experience the most stressful loss in caring for partners who have AD. However, due to its ambiguous nature, PAL often tends to 
be disregarded and goes unnoticed even as it causes immense distress to those who experience it.

\section{Literature Review}

\section{Background and Overview of the Present Study}

Despite the fact that PAL is a very stressful and common phenomenon, and that AD are widespread and chronic mental ailments that greatly affect SCPAD, there is still a paucity of studies with regard to PAL in the SCPAD population. Existing investigations have thus far focused on SCPAD in general (Agarwal et al., 2017; Fujino \& Nakamura, 2009; Highet, Thompson \& McGrath, 2002; Priest, 2012; Vermeulen, et al., 2015; Zaider, Heimberg \& Iida, 2010) and some SCPAD have been studied as a part of a larger population of caregivers of mental disorder patients in general (Chang et al., 2016; Idstad, Ask \& Tambs, 2010; Imran, Bhatti, Haider \& Azhar, 2010; Shah, Wadoo \& Latoo, 2010; Vermeulen, et al., 2015). However, in recent years, a few studies about the PAL experienced by SCPAD have been conducted (Beks, 2016; Dekel, Goldblatt, Keidar, Solomon \& Polliack, 2005; Sampson, 2013).

This investigation aims to provide a richer description of the issue of PAL in SCPAD by describing the experience in order to provide better support for the SCPAD through more effective education and interventions. Hence, the aims of this study are to identify the presence/existence of PAL among SCPAD in Jakarta and its surroundings, and to understand the manner in which this specific population experiences this particular phenomenon. Thus, the research questions are: Do SCPAD in Jakarta and surroundings experience PAL? If so, how do the SCPAD experience PAL?

\section{Methodology}

\section{A. Study Design}

This study employed the qualitative research method because of its ability to generate rich experiential data, to allow research participants to freely articulate their thoughts and feelings, and to be responsive to human subjectivity, suffering, and signification (Wertz, 2011). The interpretative phenomenological analysis IPA was the qualitative approach that was considered most suitable for this study because of its aptness for the study of a phenomenon, its ability to explore the detailed experiences of each participant, and its capacity of delving into the subjective reality of the meaning making process of the participants. More, IPA is also considered a useful method of examining complex, ambiguous, emotionally laden, difficult, and sensitive topics (Smith, Jarman \& Osborn, 1999; Smith, Flowers \& Larkin, 2009; Smith \& Osborn, 2015) such as chronic illness (Smith, 2007). PAL is regarded to be such a phenomenon due to the indefinite nature of loss that is felt, making it a major stressor that elicits mixed emotions in those who experience it. Further, AD are chronic and stigmatized mental ailments that render the experiences related to them difficult for patients and their spousal caregivers to openly discuss. 


\section{B. Informants/ Participants (Identification, Recruitment, and Selection)}

SCPAD were invited to participate in this study using the following inclusion criteria: they were required to be Indonesian men or women living in Jakarta and/or its environs; their partners were mandated to have been positively diagnosed with $\mathrm{AD}$ by mental health professionals; and they were asked to be willing to share their experiences of living with partners who were $\mathrm{AD}$ patients. No criteria were applied with regard to the minimum duration of caregiving because of the difficulty of access to the community of AD sufferers and SCPAD, which tend to be exclusive.

The first attempt made by the researchers to recruit participants through social media was rather unsuccessful due to the sensitivity of the topic of mental illness. A participant group was not available despite open appeals and also efforts made through a closed group for AD. Successful recruitment was ultimately achieved through the networking endeavors of the researchers, primarily via brochures distributed online to mental health practitioners, viand through post-interview referrals from participants who felt they had benefited from the research interview. In addition, the sensitivity of the topic also caused difficulties in building rapport with the participants. Time was needed at three levels to create effective connections with mental health practitioners as gate keepers, with the AD patients, and with the SCPAD. The duration required to build the requisite level of comfort varied from 2 weeks to 2 months. Twelve individuals, mainly AD patients, expressed interest in the study. They completed a brief informal screening via personal messaging using social media to determine their partners' eligibility for the study. Five of the 12 partners were excluded from the study because of the domicile incompatibility with the inclusion criteria, the hesitation of the AD sufferer to visit mental health professionals and thus not being positively diagnosed, or the lack of response to the researchers' efforts to contact the individual.

The study was thus finally conducted with seven participants who met the participation. However, in later stages of the investigation, data obtained from two individuals who completed the interviews were eliminated due to significant life circumstances relative to the other participants in the sample, such as a recent divorce. Moreover, another female individual contacted by a recruited female participant declined the invitation to participate because she was unwilling to dredge her SCPAD experiences as she considered them too traumatic. The final five participants were then given the option to choose the location and time for their interview based on their convenience.

Simultaneously with the enrollment of participants, three other individuals were contacted specifically for trial interviews before the field data collection due to the hardship of recruiting the actual participants. The partners of these individuals had experienced postnatal depression. The first author's interviewing skills were honed and the interview guidelines and duration were evaluated in the trial interviews.

\section{Data Collection}

Each participant was queried through individual, semi-structured interviews. This method was selected as a data collection tool for this study because it enabled the researcher to engage with 
each participant through direct dialogue, and because it is able to accord the space and flexibility for the deeper exploration of unexpected and spontaneously emergent topics (Pietkiewicz \& Smith, 2012). Despite being guided by premeditated questions to ensure the natural flow of the interview session, the format of the semi-structured interview was adaptable to the reflections of the participants as they recounted their experiences (Willig, 2010).

Each interview was conducted over four months in 2017 by the first author and was closely monitored by the second and third authors. Each participant was interviewed once, and the duration of each interview ranged from 90 to 120 minutes. Interviews were audio-taped with the prior consent of the participants in order to capture all the statements and nuances of the conversations. The interviews were conducted in Bahasa Indonesia and the selected statements were presented verbatim and translated into English.

Participants were asked questions to identify the presence of PAL, to ascertain their experiences with the phenomenon, and to understand their handling of it. In general, the questions were asked to comprehend their experiences, thoughts, feelings, behaviors, and hopes as SCPAD, particularly with regard to the changes in roles, tasks, and rituals in their households; the participants' thoughts, feelings and responses towards those changes; how they coped with the transformations; and the support they extended, sought, and received.

Further, the participants were offered the opportunity to ask questions during the interview, and these queries were answered at the end of the interview session. An oral debriefing procedure was conducted after the interview, in which each participant was informed in detail about the objectives of the study and were reminded about the offer of one counseling session per participant that they could avail of at their convenience during the course of the study.

\section{Data Analysis}

The interviews were transcribed and were analyzed using the IPA procedure (Davidsen, 2013; Osborn \& Smith, 1998; Pietkiewicz \& Smith, 2012; Smith, Jarman \& Osborn, 1999; Smith, Flowers \& Larkin, 2009) which commenced with numerous re-readings of the transcripts, the taking down of initial notes, the identification of emergent themes, the search for connections across the identified themes, the clustering of the themes, the identification of patterns, and the development of a complete narrative. The analysis process was entirely supervised by the two other authors, and was rated by two inter-raters. These supervisory and the ratifying individuals were all experienced experts from the discipline of psychology.

\section{E. Ethical Considerations/ Approval}

Approval was obtained from the Ethical Review Board of the University of Indonesia before the commencement of the study. Participants consented in writing to their engagement after they were briefed about the general aims of the study both orally and in writing. The briefing included information regarding their rights to discontinue the interview, to withdraw from the study at any time, and to refuse answer questions they considered sensitive. All participants were told prior to the interview that one counseling session was available for them during the 
research process. All five participants remained engaged until the end of the study and none sought the provided counseling session.

To ensure confidentiality, data were appropriately locked for storage, and only the three authors had full access to them. In addition, one technical editor and two inter-raters were given partial access to the data. Personal identifiers were replaced by reference values during data analysis, and the data themselves were presented as merged data.

\section{Results}

\section{A. Participants' background}

Five participants took part in this study. They were all spousal caregivers of patients suffering from AD. In terms of ethnicity, two were Chinese-Indonesians and three were indigenous Indonesians.

Table I. Participant Backgrounds

\begin{tabular}{|l|l|l|l|l|l|}
\hline SCADS & P1 & P2 & P3 & P4 & P5 \\
\hline Age & 39 & 52 & 30 & 50 & 34 \\
\hline $\begin{array}{l}\text { Gender \& } \\
\text { Relationship to } \\
\text { AD sufferers }\end{array}$ & $\begin{array}{l}\text { Male/ } \\
\text { husband }\end{array}$ & $\begin{array}{l}\text { Male/ } \\
\text { husband }\end{array}$ & $\begin{array}{l}\text { Male/ } \\
\text { husband }\end{array}$ & $\begin{array}{l}\text { Female/ } \\
\text { wife }\end{array}$ & $\begin{array}{l}\text { Male/ } \\
\text { husband }\end{array}$ \\
\hline Religion & Christian & Christian & Moslem & Christian & Christian \\
\hline Education & $\begin{array}{l}\text { Bachelor- } \\
\text { Degree }\end{array}$ & $\begin{array}{l}\text { Bachelor- } \\
\text { Degree }\end{array}$ & $\begin{array}{l}\text { Bachelor- } \\
\text { Degree }\end{array}$ & High School & $\begin{array}{l}\text { Bachelor- } \\
\text { Degree }\end{array}$ \\
\hline $\begin{array}{l}\text { Occupation } \\
\text { Marital Age }\end{array}$ & $\begin{array}{l}\text { Executive } \\
\text { (2006) }\end{array}$ & Executive & Executive & Homemaker & $\begin{array}{l}\text { Business } \\
\text { owner }\end{array}$ \\
\hline $\begin{array}{l}\text { Children } \\
\text { (1996) }\end{array}$ & - & 21 yrs & 6 yrs (2011) & 16 yrs (2001) & 5yrs (2012) \\
\hline $\begin{array}{l}\text { Year of } \\
\text { partners' AD } \\
\text { Diagnosis }\end{array}$ & $\begin{array}{l}2015 \\
\text { (2years) }\end{array}$ & $\begin{array}{l}2007 \\
(10 \text { years) }\end{array}$ & $\begin{array}{l}\text { 2016 } \\
(2 \text { years) }\end{array}$ & $\begin{array}{l}\text { 2005 } \\
\text { (12 years) }\end{array}$ & $\begin{array}{l}\text { 2017 } \\
\text { (6 months) }\end{array}$ \\
\hline $\begin{array}{l}\text { Type of } \\
\text { SCADS' } \\
\text { pamers' AD }\end{array}$ & GERD-AD & AD & AD & Panic Attack & $\begin{array}{l}\text { GAD } \\
\text { Minor } \\
\text { Depression }\end{array}$ \\
\hline
\end{tabular}

\section{B. Eight main themes}

The participants' written accounts of their lived experiences were analyzed, and eight main themes were identified: their lack of understanding of the mental and behavioral changes related to $\mathrm{AD}$; their negative views and feelings toward their partners; their feelings of loss; distress; acceptance; the paucity of support they received from others; their belief in God's sovereignty; and their hope.

1. Lack of understanding of AD-related mental and behavioral changes of their partners. All participants were aware of the AD-related mental and behavioral changes evinced by their partners, but they found it difficult to understand those changes. 
P1:'..really confusing...we asked her, 'What really is your illness?' The doctor said you're fine...I thought it's her heart."

2. Negative views and feelings towards their partners

The participants' positive views and feelings toward their partners were largely overshadowed by negative perceptions and emotions directed at their spouses as individuals.

P3:" She has too much phantasy...daydreaming."

P4:" Usually, when she's sane..."

\section{Experiences of loss}

All participants experienced variations of loss.

a) Loss of the person they once knew and expected

All participants experienced a sense of loss at the absence of the person they had once known psychologically; some of them also grieved the loss of the person they expected psychologically.

P2:"Physically, fully here... Psychologically? Here too...but sometimes not really here... simply in her own world. How can she think when all she's thinking about is her illness?

P3: "As if there's someone else. The one I once knew is missing...has changed...it's such a loss. I feel the loss of my real wife. So I feel that there's someone else. As if there's a stranger in my family."

P4: "His body is here, but his thoughts are somewhere. He's like someone I don't know. He's like a stranger, not like my husband anymore. I don't know him, that person is not my husband. I've lost the person I once knew... I want him to be the hero of our kids...As a man, he has to be tough."

P5: "I think I can feel that sometimes she's not there aja. Not in the present."

b) Loss of family rituals

All participants experienced the loss of family rituals, particularly those related to leisure activities.

P1:" I just want to be like old times, going somewhere, traveling, getting lost somewhere...I want to go out, hang out, but all she wants is returning home."

P2:" ...Constantly needing to go to the toilet... while we were supposed to be already checking out of hotel and going to the airport... " 
c) Transformation of family roles and tasks in the household

The majority of the participants experienced a transformation in the family roles and tasks in their household. Some of the participants replaced the household tasks accomplished by their partners by performing some domestic chores. One participant temporarily replaced her partner in his work at the office along with performing the role of his mother to calm her anxious partner down.

P1:" Washing clothes, the dishes...I did all the majority of the tasks."

P3: " I cook the meals for the kids too."

P4:" ...taking the role of his mother... he's the child. I pretend he's my child. If he's in panic, I'd drive and drop off our kids, assisting them with their homework, usually handled by him. I take over. At office, I handle our staffs."

d) Loss of intimacy

All participants reported feeling the loss of intimacy due to communication issues. Some participants admitted the decrease in the frequency of sexual relations.

P1: "We fought once, and then I just didn't talk. I asked her how she's doing, more than she asked me how I was doing...And husband wife (sexual interaction) intensity just lessened.

P3:"She didn't talk, no sharing whatsoever. Just silence. She didn't take care of me...when I am home after work, tired, usually she would tend to me. Now not anymore. She's just being silent."

P5:"Ooouu yes...it (sexual interaction) was just not so good...of course waaaay decreased. Very much so... Yes, I miss that for sure... More or less...because I do really want it."

e) Loss of future plans

One participant admitted feeling the loss of work-related future plans.

P1 "If I take her to Bali... and live there, work there, will she be ready or not? When the anxiety occurs in Bali without extended family, can she handle it? But she says she won't be able to handle it."

4. Distress

All of the participants experienced distress, which could be observed from their articulation of sorrow and from the mixed emotions they evinced. Their anguish could particularly be witnessed when they talked about their partners' circumstances, the caregiver's burdens, and AD-related lack of lucidity.

a) Articulated stress

All participants articulated situation-related distress. 
P1:" Postponed, postponed. It stressed me out."

P4:" When things like that happened, then I got stressed out."

P5: "It's really...tiring, I guess. Very stressful to me, I am highly stressed."

b) Mixed emotions of positive but rather negative emotions,

All participants reported feeling several different emotions ranging from positive to negative.

P3:" She never demands things...that's what make me grateful of having her as wife."

P3:" Mmm...I feel that this is because of me. How can I redeem it? ... what can I redeem?"

P4:" ...living under one roof with a person like that, is upsetting...there's disappointment, 'Why does he become like that?'...I was also shocked, 'Why is he like that?'..."

c) Talking about the situation

The five participants appeared most distressed when describing the condition of their partner, the burden of caregiving, and the lack of clarity about their partner's AD.

- Sufferer's condition

P3:" My children were only able to say..., 'Mama, what's wrong? You're afraid, aren't you?"', (teary eyes)

- Caregiver's burden

P1:" The stress is because... as if I'm having two jobs at a time."

P3:" Honestly speaking, this is exhausting. Mentally tiring. My thoughts divided between my job and home."

- $\quad$ A lack of clarity surrounding AD suffered by their partners

P3:" How long will my wife's condition lasts like this? Will she continuously have to see the psychologist? ... Will she have to be sent to mental hospital? Or what? Or how? Those are my thoughts."

5. Acceptance

All participants evinced a degree of acceptance with regard to their partner's circumstances. The majority of the participants said that they tried to accept their partner unconditionally, by accepting the changes in their partner, the AD diagnosis, and the medical treatments. However, one participant accepts his partner's situation under several conditions.

P1:" Simply accept...just 'nrimo.' I asked her, 'Do you want to see a psychologist?' Let's go."

P2:" Because she now less and less consulting to the doctor, well...I can take it. I can accept her now." 


\section{Inadequate support from others}

All the participants asserted that they did their best to support their partners as much as possible. However, despite the support they received from their friends and family, they often felt misunderstood, particularly in discussing their partner's AD.

P3: "Most of the people I talked to simply made up their own opinion, like, 'Ah...it's just her thoughts...just try to do this and that.' But it's just not the way it is in reality. 'Oh maybe your wife is staying at home for too long.' Something like that.'

P4: "Yes, people who prayed for him said that he is... lacking in faith."

\section{God's sovereignty}

Every participant appeared to believe that God was in control of their destiny, including during the partner's $\mathrm{AD}$. The participants believed that everything they were undergoing occurred according to God's plan, as a life lesson from God, to make them better and stronger human beings, with their spiritual growth as the main purpose.

P3:" ...this may be a life test from Allah. Maybe a reminder for me to not neglecting my family, not lusting for worldly things...or maybe Allah gives this because of me lacking giving charity."

P5:" This could be God's plan, it's His way of doing it to us. He is in control."

\section{Hope}

The majority of participants hoped for the recovery of their partner. Only one participant seemed more focused on his own wishes, due to his personal health issues.

P2:" I want to go to Himalaya, Nepal, ... Raja Ampat of course, Labuan Bajo of course. Rafting...including...east Europe, yes...lots of wish list...then I just have to make it happen."

P4:" His recovery. Be the one he used to be. Normal person... not like that anymore."

\section{Discussion}

\section{Conclusion}

This study sought to phenomenologically explore the experiences of five participants belonging to the SCPAD population in Jakarta and its environs. In so doing, it aimed to comprehend the lived experiences of the SCPAD participants and to understand how the process of meaning making occurs from their perspective as they live and provide the necessary care to partners who suffer from AD. Eight main themes emerged from their recounting of their experiences: their lack of understanding with regard to the AD-related mental and behavioral changes in their partners, their negative views and feelings toward their partners, their feelings of loss, distress, the lack of support they received from others, their 
acceptance of the circumstances, their faith in God's sovereignty, and their continued hope for their partner's recovery.

In general, the five participants belonging to the SACDS population of Jakarta and its surrounding areas reported experiencing variations of loss corresponding to PAL without realizing that the phenomenon they were experiencing was named PAL. This finding is aligned with Boss's (1999, 2006, 2007; Boss, Bryant, and Mancini, (2016) claim that AL is a common phenomenon that is experienced by people and is yet often overlooked, even by mental health practitioners (Carrington, 2016). Seen from the AL perspective (Boss, 1999, 2006; Boss, Bryant \& Mancini, 2016), the findings also demonstrated that all five SCPAD experienced PAL which made them feel confused, sad, and upset. Such feelings of bewilderment, sorrow, and distress stem mostly from the atmosphere of uncertainty that surrounds AD. This lack of clarity was exacerbated by the SCPAD group's lack of knowledge about $\mathrm{AD}$, the erratic behaviors displayed by the $\mathrm{AD}$ patients, and also by the burdens of caregiving felt by the participating SCPAD. Despite these issues and despite the difficulties they encountered, the SCPAD appeared to keep trying to understand their partners. In addition, the SCPAD attempted to unconditionally accept the conditions and circumstances of their partners. This mentality or attitude is known as 'nrimo' (Endraswara, 2006; in Widayanti, 2011).

Moreover, the SCPAD tried to support their partners while often feeling misunderstood when discussing their partner's AD with others. At the same time, the SCPAD coped through their religious faith by believing that God was in control even during difficult times. These findings support the extant literature pertaining to religious coping during difficult times (Harris, Allen, Dunn \& Parmelee, 2013; Kaye \& Robinson, 1994; Pearce, 2005, 2016), including the functions of religious coping with regard to the mental issues of care recipients (Ae-Ngibise, Doku, Asante \& Owusu-Agyei, 2015; Azman, Singh, Singh \& Sulaiman, 2015; Collins \& Bowland, 2012; Johnson, 2000; Maunu \& Stein, 2010; Mohamad, Zabidah, Fauziah \& Sarnon, 2012; Murray-Swank et al., 2006; Pearce, Medoff \& Dixon, 2016). In addition, the SCPAD attempt to maintain their hope, especially for the recovery of their partner. This continued optimism corresponds with exisiting scholarly literature on the caregiver's hope (Bland \& Darlington, 2002; Boss, 2016; Geffken et al., 2006; Masten, 2016). In general, the five SCPAD seemed able to endure the difficulties posed by PAL through acceptance, religious coping, and hope.

\section{Value Addition}

This study adds much value to the scholarly understanding of PAL and its effects on the SCPAD. First, such an investigation has never before been conducted in Indonesia. Second, it identifies the existence of PAL among the SCPAD in Jakarta and its surrounding areas. Third, it bridges the existing research gap with regard to the PAL experienced by SCPAD and it enriches the existing research literature about SCPAD. Fourth, it identifies both the particularities and commonalities among the SCPAD, including their faith in God's sovereignty, their misinterpretation and underestimation of AD-related symptoms, and their acceptance or nrimo, an attitude unique to Indonesian culture. Fifth, this study contributes to 
society by raising public awareness about PAL in the SCPAD population. Such knowledge is pertinent and directed also at the SCPAD and at mental health practitioners. Finally, the present investigation also supports previous research findings that have highlighted the need to support patients of AD as well as their SCPAD (Chadda, 2014; Chang et al., 2016; Hunt, Greene \& Whiting, 2016; Senaratne, van Ameringen, Mancini \& Patterson, 2010; Vermeulen et al., 2013; Vikas, Avasthi \& Sharan, 2011) and it encourages AL-related psychoeducational interventions for $\mathrm{AD}$ sufferers and their SCPAD, corresponding to previous research results obtained with regard to mental health literacy (Jorm, 2011) and also to Boss' intervention guidelines with respect to resilience (Boss,1999, 2007, 2010, 2016; Boss, Bryant \& Mancini, 2016).

\section{Limitations, Recommendations \& Implications}

This study acknowledges several limitations. First, the partners of the participants may have suffered from different types of AD. Previous research has found that the caregivers's response to AD patients would vary according to the type of AD (Lebowitz, Panza \& Bloch, 2015; Taylor, Koch \& McNally, 1992; Vikas, Avasthi \& Sharan, 2011). Thus, future research should recruit participants with partners who suffer from one particular type of AD to enable more in-depth exploration of the SCPAD experience.

Second, there was an over-representation of working male participants in this study. As breadwinners of their families, all male participants expressed their distress in trying to balance work and being present for their partners. This articulation confirms the outcomes of a previous study that suggested that male SCPAD are more prone to distress due to difficulties in allocating time between work and attending to their partners (Agarwal et al., 2017). Further research must address the work-related gender differences among the SCPAD population to enable deeper explorations of work-related caregiver burdens.

Third, the study's participants were homogenous in their religious faith; thus, one religion was over-represented. According to Boss (2004, 2007; Boss, Bryant, and Mancini, (2016), faith, belief systems, and cultural values can influence how far an individual is able to tolerate AL. Therefore, further research should consider the recruitment of participants of different ethnic and religious backgrounds in Indonesia, including Indonesian atheists.

Despite the limitations of the present investigation, its use of IPA and the AL perspective in studying the PAL experienced by the SCPAD in Jakarta and its environs has elucidated the existence of PAL in this population. This newly obtained knowledge could be useful in disseminating public awareness about this phenomenon within this population. Such new understanding would also be beneficial to mental health practitioners, and would help them provide better support for the SCPAD through PAL-related psychoeducation and interventions. In turn, the support would help the SCPAD in assist their partners toward recovery 


\section{References}

Ae-Ngibise, K. A., Doku, V. C. K., Asante, K. P., \& Owusu-Agyei, S. (2015). The experience of caregivers of people living with serious mental disorders: a study from rural Ghana. Global Health Action, 8(1), 26957. https://doi.org/10.3402/gha.v8.26957

Agarwal, M., Kushwaha, A., Nischal, A., Kar, S., Gupta, B., Tripathi, A., ... Agarwal, A. (2017). Burden of care in the caregivers of patients with anxiety disorders. Indian Journal of Social Psychiatry, 33(1). doi: 10.4103/0971-9962.200092.

American Psychiatric Association (2013). Diagnostic and statistical manual of mental disorders (fifth edn.). Arlington, VA: American Psychiatric Association.

Anxietas Forum Indonesia. Retrieved from facebook.com.

Azman, A., Jamir Singh, P. S., \& Sulaiman, J. (2017). Caregiver coping with the mentally ill: a qualitative study. Journal of Mental Health, 26(2), 98-103.

Baker, A. E. Z., Procter, N., \& Gibbons, T. (2009). Dimensions of loss from mental illness. The Journal of Sociology and Social Welfare, 36(4), 25. Retrieved from http://scholarworks.wmich.edu/jssw/vol36/iss4/4.

Bandelow, B., \& Michaelis, S. (2015). Epidemiology of anxiety disorders in the 21st century. Dialogues in Clinical Neuroscience, 17(3), 327-335. Retrieved from https://www.ncbi.nlm.nih.gov/pmc/articles/PMC4610617/

Baxter, A. J., Vos, T., Scott, K. M., Ferrari, A. J., \& Whiteford, H. A. (2014). The global burden of anxiety disorders in 2010. Psychological Medicine, 44(11), 2363-2374.

Beks, T. A. (2016). Walking on eggshells: the lived experience of partners of veterans with PTSD. The Qualitative Report, 21(4), 645-660. Retrieved from http://nsuworks.nova.edu/tqr/vol21/iss4/4.

Bland, R., \& Darlington, Y. (2002). The nature and sources of hope: Perspectives of family caregivers of people with serious mental illness. Perspectives in Psychiatric Care, 38(2), 61-68.

Boss, P. (1999). Ambiguous loss, learning to live with unresolved grief. Cambridge, MA: Harvard University Press.

Boss, P. (2004). Ambiguous loss research, theory, and practice: reflections after 9/11. Journal of Marriage and Family, 66(3), 551-566. doi: 10.1111/j.0022-2445.2004.00037.x.

Boss, P. (2006). Loss, trauma, and resilience: Therapeutic work with ambiguous loss. WW Norton \& Company.

Boss, P. (2007). Ambiguous loss theory: Challenges for scholars and practitioners. Family Relations, 56(2), 105-111.

Boss, P. (2016). The context and Process of Theory Development: The Story of Ambiguous Loss. Journal of Family Theory and Review, 8(3), 269-286. doi: 10.1111/jftr.12152.

Boss, P., Bryant, C. M., \& Mancini, J. A. (2016). Family stress management: A contextual approach. LA: Sage Publications.

Butters, M. A., Bhalla, R. K., Andreescu, C., Wetherell, J. L., Mantella, R., Begley, A. E., \& Lenze, E. J. (2011). Changes in neuropsychological functioning following treatment for late-life generalised anxiety disorder. The British Journal of Psychiatry, 199(3), 211-218.

Carrington, C. P. (2016). A counselor's first encounter with non-death loss: a phenomenological case study on new counselor preparation and experience in working with non-death loss. Counseling \& Human Services Theses \& Dissertations. Retrieved from digitalcommons.odu.edu/chs_etds/6. Old Diminion University. doi: 10.15777/srj1-0529.

Chadda, R. K. (2014). Caring for the family caregivers of persons with mental illness. Indian Journal of Psychiatry, 56(3), 221-227. doi: 10.4103/0019-5545.140616. PubMed: 25316932.

Chang, S., Zhang, Y., Jeyagurunathan, A., Lau, Y. W., Sagayadevan, V., Chong, S. A., ... Subramaniam, M. (2016). Providing care to relatives with mental illness: reactions and distress among primary informal caregivers. BMC Psychiatry, 16(1), 80. doi: 10.1186/s12888-016-0786-9. PubMed: 27016185.

Collins, W. L., \& Bowland, S. (2012). Spiritual practices for caregivers and care receivers. Journal of Religion, Spirituality and Aging, 24(3), 235-248. doi: 10.1080/15528030.2012.648585.

Cridland, E. K., Jones, S. C., Magee, C. A., \& Caputi, P. (2014). Family-focused autism spectrum disorder research: A review of the utility of family systems approaches. Autism, 18(3), 213-222. 
Davidsen, A. S. (2013). Phenomenological approaches in psychology and health sciences. Qualitative Research in Psychology, 10(3), 318-339. doi: 10.1080/14780887.2011.608466. PubMed: 23606810.

Dekel, R., Goldblatt, H., Keidar, M., Solomon, Z., \& Polliack, M. (2005). Being a wife of a veteran with posttraumatic stress disorder. Family Relations, 54(1), 24-36. doi: 10.1111/j.0197-6664.2005.00003.x.

Fadden, G., Bebbington, P., \& Kuipers, L. (1987). The burden of care: the impact of functional psychiatric illness on the patient's family. The British Journal of Psychiatry, 150(3), 285-292.

Fujino, N., \& Okamura, H. (2009). Factors affecting the sense of burden felt by family members caring for patients with mental illness. Archives of Psychiatric Nursing, 23(2), 128-137.

Geffken, G. R., Storch, E. A., Duke, D. C., Monaco, L., Lewin, A. B., \& Goodman, W. K. (2006). Hope and coping in family members of patients with obsessive-compulsive disorder. Journal of Anxiety Disorders, 20(5), 614-629.

Gualtieri, C. T., \& Morgan, D. W. (2008). The frequency of cognitive impairment in patients with anxiety, depression, and bipolar disorder: an unaccounted source of variance in clinical trials. Journal of Clinical Psychiatry, 69(7), 1122-1130.

Harris, G. M., Allen, R. S., Dunn, L., \& Parmelee, P. (2013). “Trouble Won’t Last Always” Religious Coping and Meaning in the Stress Process. Qualitative Health Research, 23(6), 773-781.

Highet, N. J., Thompson, M., \& McGrath, J. (2002). The impact of living with anxiety-carers' perspective. Retrieved from https://www.beyondblue.org.au/about-us/research-projects/research-projects/theimpact-of-living-with-anxiety-carers-perspectives

Hofmeijer-Sevink, M. K., Batelaan, N. M., van Megen, H. J., Penninx, B. W., Cath, D. C., van den Hout, M. A., \& van Balkom, A. J. (2012). Clinical relevance of comorbidity in anxiety disorders: a report from the Netherlands Study of Depression and Anxiety (NESDA). Journal of Affective Disorders, 137(1-3), 106-112.

Hunt, G. G., Greene, R., \& Whiting, C. G. (2016). On pins and needles: caregivers of adults with mental illnes. National Alliance for caregiving. Retrieved from https://www.caregiving.org/wpcontent/uploads/2016/02/NAC.

Idstad, M., Ask, H., \& Tambs, K. (2010). Mental disorder and caregiver burden in spouses: the Nord-Trøndelag health study. BMC Public Health, 10(1), 516.

Imran, N., Bhatti, M. R., Haider, I. I., Azhar, L., Omar, A., \& Sattar, A. (2010). Caring for the caregivers: Mental health, family burden and quality of life of caregivers of patients with mental illness. Journal of Pakistan Psychiatric Society, 7(1), 23-28.

Johnsen, G. E., \& Asbjørnsen, A. E. (2008). Consistent impaired verbal memory in PTSD: A meta-analysis. Journal of Affective Disorders, 111(1), 74-82. doi: 10.1016/j.jad.2008.02.007. PubMed: 18377999.

Johnson, E. D. (2000). Differences among families coping with serious mental illness: A qualitative analysis. American Journal of Orthopsychiatry, 70(1), 126-134. doi: 10.1037/h0087664. PubMed: 10702857.

Jorm, A. F. (2012). Mental health literacy: Empowering the community to take action for better mental health. American Psychologist, 67(3), 231.

Kasper, S. (2006). Anxiety disorders: under-diagnosed and insufficiently treated. International Journal of Psychiatry in Clinical Practice, 10(sup1), 3-9.

Kaye, J., \& Robinson, K. M. (1994). Spirituality among caregivers. Image: The Journal of Nursing Scholarship, 26(3), 218-221.

Kementrian Kesehatan Republik Indonesia. (2013). Hasil Riskesdas 2013. Retrieved from http://www.depkes.go.id/resources/download/general/Hasil\%20Riskesdas\%202013.pdf.

Kerig, P. K., Ludlow, A., \& Wenar, C. (2012). Developmental psychopathology: From infancy through adolescence ( $6^{\text {th }}$ ed.). Maidenhead, UK: McGraw-Hill.

Kessler, R. C., Petukhova, M., Sampson, N. A., Zaslavsky, A. M., \& Wittchen, H. U. (2012). Twelve- month and lifetime prevalence and lifetime morbid risk of anxiety and mood disorders in the United States. International Journal of Methods in Psychiatric Research, 21(3), 169-184.

Kessler, R. C., Ruscio, A. M., Shear, K., \& Wittchen, H. U. (2010). Epidemiology of anxiety disorders. Current Topics in Behavioral Neurosciences, 2, 21-35. doi: 10.1007/7854_2009_9. PubMed: 21309104.

Kring, A., Johnson, S., Davidson, G., \& Neale, J. (2014). Abnormal Psychology (12th Ed. DSM-5 Update). USA: Wiley. 
Lebowitz, E. R., Panza, K. E., \& Bloch, M. H. (2016). Family accommodation in obsessive-compulsive and anxiety disorders: a five-year update. Expert Review of Neurotherapeutics, 16(1), 45-53.

Masten, A. S. (2016). Resilience in the context of ambiguous loss: A commentary. Journal of Family Theory \& Review, 8(3), 287-293.

Maunu, A., \& Stein, C. H. (2010). Coping with the personal loss of having a parent with mental illness: Young adults' narrative accounts of spiritual struggle and strength. Journal of Community Psychology, 38(5), 645-655.

McLean, C. P., Asnaani, A., Litz, B. T., \& Hofmann, S. G. (2011). Gender differences in anxiety disorders: Prevalence, course of illness, comorbidity and burden of illness. Journal of Psychiatric Research, 45(8), 1027-1035.

Mohamad, M. S., Zabidah, P., Fauziah, I., \& Sarnon, N. (2012). Mental health literacy among family caregivers of schizophrenia patients. Asian Social Science, 8(9), 74.

Muller, J., \& Roberts, J. E. (2005). Memory and attention in obsessive-compulsive disorder: a review. Journal of Anxiety Disorders, 19(1), 1-28. doi: 10.1016/j.janxdis.2003.12.001. PubMed: 15488365.

Murray-Swank, A. B., Lucksted, A., Medoff, D. R., Yang, Y. E., Wohlheiter, K., \& Dixon, L. B. (2006). Religiosity, psychosocial adjustment, and subjective burden of persons who care for those with mental illness. Psychiatric Services, 57(3), 361-365.

National Institute of Mental Health (2016). Anxiety Disorders. Retrieved from http://www.nimh.nih.gov/health/topics/anxiety-disorders/index.shtml.

Ollendick, T. H., \& Benoit, K. E. (2012). A parent-child interactional model of social anxiety disorder in youth. Clinical Child and Family Psychology Review, 15(1), 81-91.

Osborn, M., \& Smith, J. A. (1998). The personal experience of chronic benign lower back pain: An interpretative phenomenological analysis. British Journal of Health Psychology, 3(1), 65-83.

Pearce, M. J. (2005). A critical review of the forms and value of religious coping among informal caregivers. Journal of Religion and Health, 44(1), 81-117. doi: 10.1007/s10943-004-1147-4.

Pearce, M. J., Medoff, D., Lawrence, R. E., \& Dixon, L. (2016). Religious coping among adults caring for family members with serious mental illness. Community Mental Health Journal, 52(2), 194-202.

Pietkiewicz, I., \& Smith, L. A. (2012). A practical guide to using Interpretative Phenomenological Analysis in qualitative research psychology. Psychological Journal. Retrieved from: https://www.researchgate.net/file.PostFileLoader.html.

Priest, J. B. (2013). Anxiety disorders and the quality of relationships with friends, relatives, and romantic partners. Journal of Clinical Psychology, 69(1), 78-88.

Reavley, N., Cvetkovski, S., Jorm, T., \& Mackinnon, A. (2010). Update the National Depression Index and develop the National Anxiety Index. Orygen Youth Health Research Centre. Retrieved from www.beyondblue.org.au/about-us/research-projects/research-projects/update-the-national-depressionindex-and-develop-the-national-anxiety-index.

Rector, N., Bourdeau, D., Kitchen, K., \& Joseph-Massiah, L. (2008). Anxiety Disorders: an Information Guide; a Guide for people with anxiety and their families. Retrieved from https:/www.camh.ca//media/files/guides-and-publications. Canada: $C A M H$.

Remes, O., Brayne, C., van der Linde, R., \& Lafortune, L. (2016). A systematic review of reviews on the prevalence of anxiety disorders in adult populations. Brain and Behavior, 6(7), e00497. doi: $10.1002 / \mathrm{brb3} .497$.

Rowe, J. (2012). Great expectations: A systematic review of the literature on the role of family carers in severe mental illness, and their relationships and engagement with professionals. Journal of Psychiatric and Mental Health Nursing, 19(1), 70-82.

Sampson, J. M. (2013). The lived experience of family members of persons who compulsively hoard: A qualitative study. Journal of Marital and Family Therapy, 39(3), 388-402.

Senaratne, R., van Ameringen, M., Mancini, C., \& Patterson, B. (2010). The burden of Anxiety Disorders on the Family. Journal of Nervous and Mental Disease, 198(12), 876-880. doi: 10.1097/NMD.0b013e3181fe7450. PubMed: 21135638. 
Shah, A. J., Wadoo, O., \& Latoo, J. (2010). Psychological distress in carers of people with mental disorders. British Journal of Medical Practitioners, 3(3). Retrieved from http://bjmp.org/files/2010-3-3/bjmp2010-3-3-a327.pdf.

Smith, J. A. (1996). Beyond the divide between cognition and discourse: Using interpretative phenomenological analysis in health psychology. Psychology and health, 11(2), 261-271.

Smith, J. A., \& Osborn, M. (2015). Interpretative phenomenological analysis as a useful methodology for research on the lived experience of pain. British Journal of Pain, 9(1), 41-42.

Smith, J. A., Flowers, P., \& Larkin, M. (2009). Interpretative phenomenological analysis: Theory, method and research. London, UK: Sage Publications.

Smith, J. A., Jarman, M., \& Osborn, M. (1999). Doing interpretative phenomenological analysis. In M. Murray \& K. Chamberlain (eds.), Qualitative health psychology: Theories and methods (pp.218-240). London, UK: Sage Publications

Taylor, S., Koch, W. J., \& McNally, R. J. (1992). How does anxiety sensitivity vary across the anxiety disorders? Journal of Anxiety Disorders, 6(3), 249-259. doi: 10.1016/0887-6185(92)90037-8.

Tempesta, D., Mazza, M., Serroni, N., Moschetta, F. S., Di Giannantonio, M., Ferrara, M., \& De Berardis, D. (2013). Neuropsychological functioning in young subjects with generalized anxiety disorder with and without pharmacotherapy. Progress in Neuro-Psychopharmacology and Biological Psychiatry, 45, 236-241.

Vermeulen, B., Lauwers, H., Spruytte, N., \& Van Audenhove, C. (2015). Experiences of family caregivers for persons with severe mental illness: an international exploration. European Neuropsychopharmacology, 25, S374-S374.

Vikas, A., Avasthi, A., \& Sharan, P. (2011). Psychosocial impact of obsessive-compulsive disorder on patients and their caregivers: a comparative study with depressive disorder. International Journal of Social Psychiatry, 57(1), 45-56. doi: 10.1177/0020764009347333. PubMed: 21252355.

Wertz, F. J. (2011). The qualitative revolution and psychology: Science, politics, and ethics. The Humanistic Psychologist, 39(2), 77-104.

Widayanti, C. G. (2011). The perceived role of God in health and illness: the experience of Javanese mothers caring for a child with thalassemia. Jurnal Psikologi, 9(1). Retrieved from ejournal.undip.ac.id. doi: 10.14710/jpu.9.1.

Willig, C. (2010). Introducing qualitative research in psychology. Maidenhead, UK: McGraw Hill.

Wittchen, H. U., Jacobi, F., Rehm, J., Gustavsson, A., Svensson, M., Jönsson, B., ... \& Fratiglioni, L. (2011). The size and burden of mental disorders and other disorders of the brain in Europe 2010. European Neuropsychopharmacology, 21(9), 655-679.

Yang, Y., Zhang, X., Zhu, Y., Dai, Y., Liu, T., \& Wang, Y. (2015). Cognitive impairment in generalized anxiety disorder revealed by event-related potential N270. Neuropsychiatric Disease and Treatment, 11, 1405.

Zaider, T. I., Heimberg, R. G., \& Iida, M. (2010). Anxiety disorders and intimate relationships: A study of daily processes in couples. Journal of Abnormal Psychology, 119(1), 163-173. 